\title{
KNOWLEDGE, ATTITUDE AND PRACTICE ABOUT HEALTH PROMOTION AMONGST PHYSIOTHERAPISTS IN SOUTH AFRICA
}

\begin{abstract}
The increasing prevalence of non-communicable chronic diseases, particularly in middle-income countries like South Africa, calls for physiotherapists in the 21st century to adopt a health promotion (HP) approach in patient treatment. However, little is known about physiotherapists' actual knowledge, attitude and practice about HP in physiotherapy practice in South Africa (SA).

METHODS: In a cross-sectional survey, 500 registered physiotherapists in $S A$ were randomly selected to respond to a self-administered questionnaire on socio-demographic and educational background, knowledge, attitude and practices regarding HP. Stata IC version 10 was used for analyses.

RESULTS: The majority of physiotherapists (92\%) possessed adequate knowledge about HP as they responded correctly to almost all the HP statements and $79 \%$ exhibited a positive attitude towards HP practice. However, 47\% reflected adequate HP integration practice in their work. Age $(p=.02)$ and work experience $(p=.01)$ predict adequate knowledge and

\author{
Taukobong, NP (PT, MPHYST) ${ }^{1}$ \\ Myezwa, H (PT, PhD) ${ }^{2}$ \\ Prof Pengpid, S (DPH, MBA) ${ }^{3}$ \\ Van Geertruyden, JP (MD, PhD) ${ }^{4}$
}

Department of Physiotherapy, University of Limpopo-

Medunsa Campus, Pretoria, South Africa

2 Department of Physiotherapy, University of

Witwatersrand, Johannesburg, South Africa

3 Department of Public Health, University of Limpopo-

Medunsa Campus, Pretoria, South Africa

4 International Health, Epidemiology en Social

Medicine, University of Antwerp, Antwerp, Belgium

attitude was significantly associated with knowledge ( $p=.002)$. After stepwise modelling, HP training at undergraduate level (aOR: 3.97; $p .0001)$, over 10 years of experience (aOR: 2.57; $=.002)$ and positive attitude (aOR: $2.54: p=.007)$ were identified as predictors of adequate health promotion practices.

CONCLUSION: South African physiotherapists have good knowledge and a suitable attitude towards health promotion but only a few integrate health promotion in their practice. Short training and continuous education courses are needed for physiotherapists to improve their understanding as well as health promotion practice. Such skills would enable them to help alleviating the noncommunicable chronic disease burden striking South Africa.
\end{abstract}

\section{KEYWORDS: HEALTH PROMOTION, KNOWLEDGE, ATTITUDE, PRACTICE, PHYSIOTHERAPY}

\section{INTRODUCTION}

The South African (SA) health system is challenged by a quadruple burden of diseases, namely HIV/AIDS and TB, chronic non-communicable diseases (NCDs), violence and injury, and peri-

\section{Corresponding author:}

Nomathemba PatriciaTaukobong

University of Limpopo -

Medunsa Campus,

PO Box 239.

Medunsa,

0204

Email: Nomathemba.Taukobong@ul.ac.za natal and maternal conditions. NCDs account for $11-13 \%$ of SA's burden of diseases and contribute towards high levels of mortality and morbidity $(\mathrm{DOH}$, 2010) . The World Health Organization (WHO) estimates that in 2015, worldwide, the majority of the 64 million deaths will be caused by NCDs (WHO, 2011). Already today, NCDs are costing health departments large sums of money annually (Church and Blair, 2009) not only in high income countries (HIC) but also in in low and middle-income countries (LIC/MIC). NCDs are related to lifestyle and tend to develop over a long period, have an unclear relation- ship between cause and effects, can rarely be cured, and thus require preventive approaches and strategies (Ritchie, 1989). Consequently, an increasing number of people with lifestyle- related conditions presenting at health care centres, need continuous support enabling them to take an active role in chronic disease management (Dean et al., 2011).

The increasing prevalence of NCDs requires a more expanded scope and systematic provision of interventions such as health promotion (HP). The SA Department of Health's 10- point strategic plan (DOH, 2010) identifies HP as a strategy to improve the population's 
$\mathrm{P}$
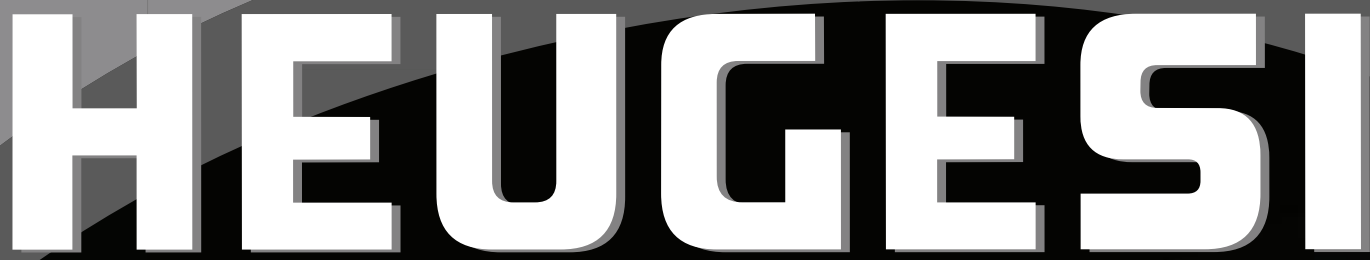

\section{Piroxicam $5 \mathrm{mg} / \mathrm{g}$}

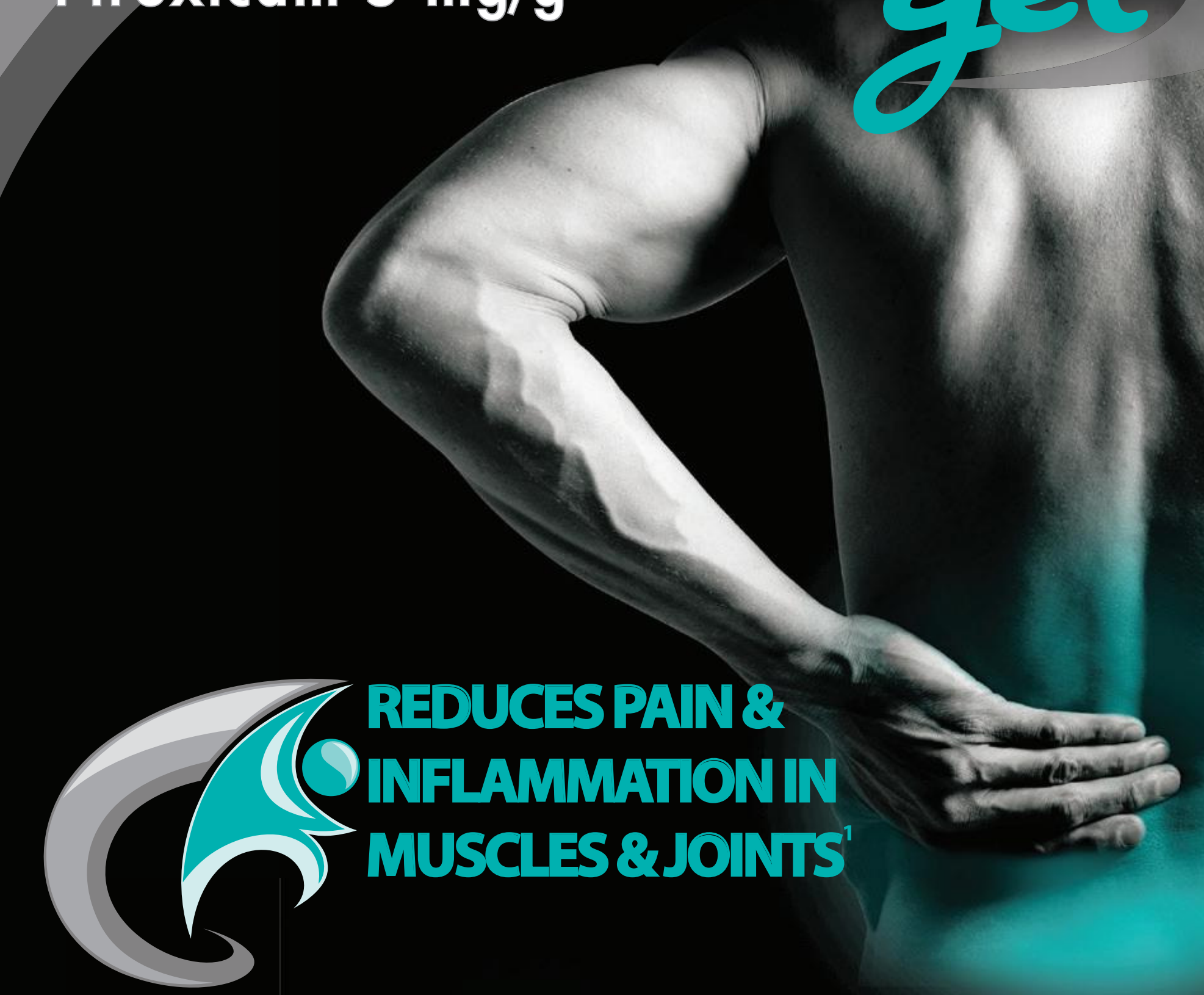

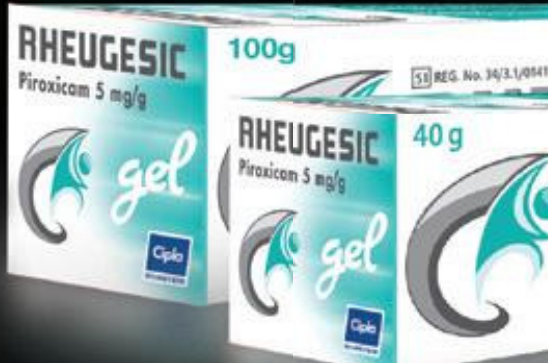

Piroxicom 5 mals
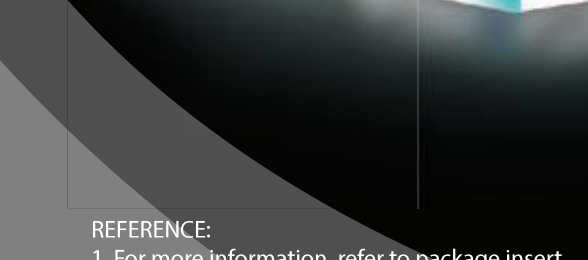

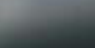

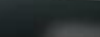

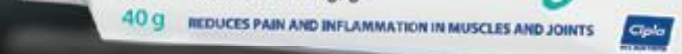


Table 1: Characteristics of participating physiotherapists, South Africa, 2012 ( $n=264)$

\begin{tabular}{|c|c|c|}
\hline Variables & & N (\%) \\
\hline \multirow[t]{2}{*}{ Gender } & Male & $48(18)$ \\
\hline & Female & $216(82)$ \\
\hline \multirow[t]{4}{*}{ Age group } & $21-30$ years & 99(37) \\
\hline & $31-40$ years & $78(30)$ \\
\hline & $41-50$ years & $39(15)$ \\
\hline & $>50$ years & $48(18)$ \\
\hline \multirow[t]{4}{*}{ Ethnic groups } & African & 102(39) \\
\hline & Asian & $9(3)$ \\
\hline & Coloured & $6(2)$ \\
\hline & White & $147(56)$ \\
\hline \multirow[t]{9}{*}{ Physiotherapy degree institution } & Pretoria & $37(14)$ \\
\hline & Western Cape & $7(3)$ \\
\hline & Stellenbosch & $35(13)$ \\
\hline & Cape Town & $27(10)$ \\
\hline & Kwazulu Natal & $13(5)$ \\
\hline & Witwatersrand & $29(11)$ \\
\hline & Medunsa & $79(30)$ \\
\hline & Free State & $19(7)$ \\
\hline & Others & $18(7)$ \\
\hline \multirow[t]{5}{*}{ Years of experience as physiotherapist } & 0-5years & $75(28)$ \\
\hline & 6-10years & $53(21)$ \\
\hline & 11-15years & $43(16)$ \\
\hline & 16-20years & $22(8)$ \\
\hline & $>20$ years & $71(27)$ \\
\hline \multirow[t]{2}{*}{ Current working sector* } & Public & $136(52)$ \\
\hline & Private & $148(56)$ \\
\hline \multirow[t]{5}{*}{ Setting of current work** } & In-patient & $145(55)$ \\
\hline & Out-patient & $189(72)$ \\
\hline & Community & $44(17)$ \\
\hline & University & $12(4)$ \\
\hline & Other & $7(3)$ \\
\hline \multirow[t]{2}{*}{ Ever received health promotion training } & Yes & $182(69)$ \\
\hline & No & $82(31)$ \\
\hline \multirow[t]{2}{*}{ Ever received health promotion certificate\# } & Yes & $21(8)$ \\
\hline & No & $242(92)$ \\
\hline \multirow[t]{2}{*}{$\begin{array}{l}\text { Ever attended CE courses on health } \\
\text { promotion }\end{array}$} & Yes & $76(29)$ \\
\hline & No & $188(71)$ \\
\hline
\end{tabular}

* The total number include physiotherapists working both in private and public sector

** This number include physiotherapist working in more than one setting

\# There is one missing response

health. HP goes beyond health care and requires people to be aware of health consequences of their decisions and accept responsibilities for managing and maintaining their own health. In addition, the WHO recommends that health care services incorporate a HP component as a key to service for all patients to minimise or prevent the high morbidity and mortality rates associated with NCDs (WHO, 2007). Provision of information, education for health, and improvement of life
Health professionals such as general practitioners, practice nurses, dieticians, and including physiotherapists are therefore encouraged to adopt person-centred and person-empowered approaches to health care in order to address the current health priorities (Dean, 2009; Perreault, 2008). The starting point of a physiotherapy intervention is usually ill-health, with the intention to return the patient to a functional level. While rehabilitation may be the area of greatest need in physiotherapy, health promotion and disease prevention may and should be addressed as well. It is for this reason that physiotherapists are being called upon to be knowledgeable about, and to integrate, prevention and health promotion into their daily practice (Ritchie,1989; Laliberte et al., 2012; Perreault, 2008). The World Confederation of Physical Therapists (WCPT) supports the integration of HP in physiotherapy practice, as physiotherapists are well trained to provide HP covering the areas of health education and disease prevention (WCPT, 2007). Strategies used in physiotherapy are non-invasive and cost-effective (Dean 2009). Integration of HP during physiotherapy routine may develop and change lifestyles and have an effect on social, economic and environmental conditions that determine health (Frantz, 2008). Given the increasing prevalence of lifestyle-related NCDs and the increasing burden on the health care system, physiotherapists are well positioned to play a role in health promotion. There is a need to develop sustainable HP practices for physiotherapists (Taukobong et al., 2014) especially in a country plagued by multiple epidemics. This would require a set of skills and the improved knowledge, attitudes necessary to enable the physiotherapists to support the broad HP practice. Furthermore comprehensive knowledge, positive attitude and integration of HP in daily practice are essential if physiotherapists are to contribute towards the fight against NCDs and concurrently address the associated conditions in their daily routine. However, little is known about physiotherapists' actual knowledge, attitude and practice (KAP) about HP in physiotherapy practice, and no data are available in South 
Africa (SA). Therefore, the current study assessed, for the first time, SA's physiotherapists on their KAP about health promotion practice.

\section{METHODOLOGY Study design}

A quantitative, cross sectional knowledge, attitude and practice (KAP) survey was conducted by email and post, from October 2011 to January 2012. A selfaddressed envelope was enclosed with the posted questionnaires to enhance responses, and the participants were allowed a month to respond and reminders were sent to non-respondents.

\section{Participants}

Our study sample consisted of a random sample of 500 physiotherapists selected from the 5242 practitioners on the Health Professions Council of South Africa (HPCSA) register during the month of April 2011. The final sample consisted of 264 physiotherapists from public, private, community and tertiary institutions. Based on the literature, a questionnaire was developed to test the physiotherapists on knowledge, attitude and practice about HP. To test the reliability and validity of the tool, the questionnaire was peer reviewed by two physiotherapists who are lecturers and researchers in HP. No major recommendations were provided, but slight rephrasing of statements was suggested. Following the suggestions by the peer reviewers, the questionnaire was tested with a pilot study among 10 physiotherapists at the Dr George Mukhari hospital in Gauteng, South Africa. Processing of the responses from the pilot study indicated that the tool was reliable and valid, hence no re-test was conducted, and the questionnaire was adopted and used for data collection.

\section{Questionnaire Measures}

Knowledge was assessed using 10 statements e.g. "Health promotion activity involves building healthy policy to promote health of the population"; "HP intervention calls for professionals to be involved in improving and maintaining healthy status for all". Response options were $0=$ unknown, $1=$ no and $2=$ yes. Cronbach's alpha in this sample for knowledge was 0.73 .

Attitude towards integrating HP in physiotherapy practice: Participants were asked to rate their response to a set of 10 statements from $0=$ neutral, $1=$ disagree and 2=agree. Cronbach's alpha was 0.76 for attitude in this sample.

Health promotion practice: A measure of HP practice was derived from eleven statements about HP integration in physiotherapy practice e.g. "HP is integrated in physiotherapy treatment when the patient is aware of the problem and desires to improve". Response options were $0=$ never, $1=$ often and $2=$ always $($ Cronbach's alpha $=0.85$ ).

\section{Data analysis}

Response proportions for each domain were calculated using the maximum possible scores where knowledge = 20; attitude $=20$ and practice $=22$. The total scores were analysed using a 3 point Likert scale indicating the levels of competency as follows: 1= marginal/ negative $(\leq 49) ; 2=$ adequate/neutral $(\leq$ $79) ; 3=$ high/positive $(>80)$. The results were then represented in tabular formats. After examining the response frequencies and before examining the association between variables, some variables were categorised to allow for further analysis, using them as independent measures in logistic regression analysis. Evaluation of the statistical significance of the difference between subgroups included the chi-square test for frequencies and logistic regression modelling. Logistic regression modelling was used to investigate functional relationships associated with physiotherapists' knowledge, attitude and practice scores, controlling for socio-demographic characteristics. The corresponding odds ratio (OR) and their $95 \%$ confidence intervals $(95 \% \mathrm{CI})$ were determined. Data were analysed using the Stata IC version 10 (Stata Corp, Lakeway, College Station, Texas, USA).

\section{RESULTS}

The study recorded a response rate of $53 \% \quad(n=264)$ from physiotherapists working in different sectors and various settings within the health care services. In general, response rates were poor among health care professionals, and had deteriorated over time (Cook et al, 2009).

\section{Demographic characteristics}

The majority of the participants were females (82\%) (Table1). Participants' age ranged from 21 years to older than 50 years, with two thirds being under 40 years $(67 \%)$. The primary physiotherapy degrees were obtained from the eight training institutions in SA among which the most $(30 \%)$ were from Medunsa and the least $(3 \%)$ from the University of Western Cape (UWC). Work experience ranged from one year to more than 20 years, and most had less than 16 years of work experience (65\%). Almost an equal number of respondents worked in the private sector $(56 \%)$ and/or public sector (52\%). Most participants (72\%) worked in an out-patient setting, a few (4\%) lectured at university, and $17 \%$ worked in a community based setting. Health promotion (HP) was covered during training among many $(69 \%)$ while about one out of ten $(8 \%)$ obtained a certificate in HP. Most $(71 \%)$ of the participants had not attended continuous education (CE) courses on HP.

The knowledge, attitude and practice scores of the participants are shown in Table 2.

\section{Knowledge}

The majority (97\%) were aware that HP intervention calls for professionals to be involved in improving and maintaining healthy status for all patients and that HP intervention involves strengthening community action to prevent diseases. When responding to the statement about achieving HP through environmental modification, only $78 \%$ answered 'yes', indicating a lower response compared to other responses. The majority (97\%) knew that HP includes the implementation of lifestyle and behavioural change programmes. With regard to HP as an approach to develop personal skills, the majority (94\%) answered 'yes' and many (93\%) also knew that health education (HE) is a health promotion strategy. Approximately nine out of ten participants knew that health promotion involves early detection and disease prevention (91\%) and that HP involves supporting health policy $(90 \%)$. The majority (92\%) scored high, indicating they were knowledgeable about HP, with a median score of $10(\mathrm{SD}=0.73)$. 


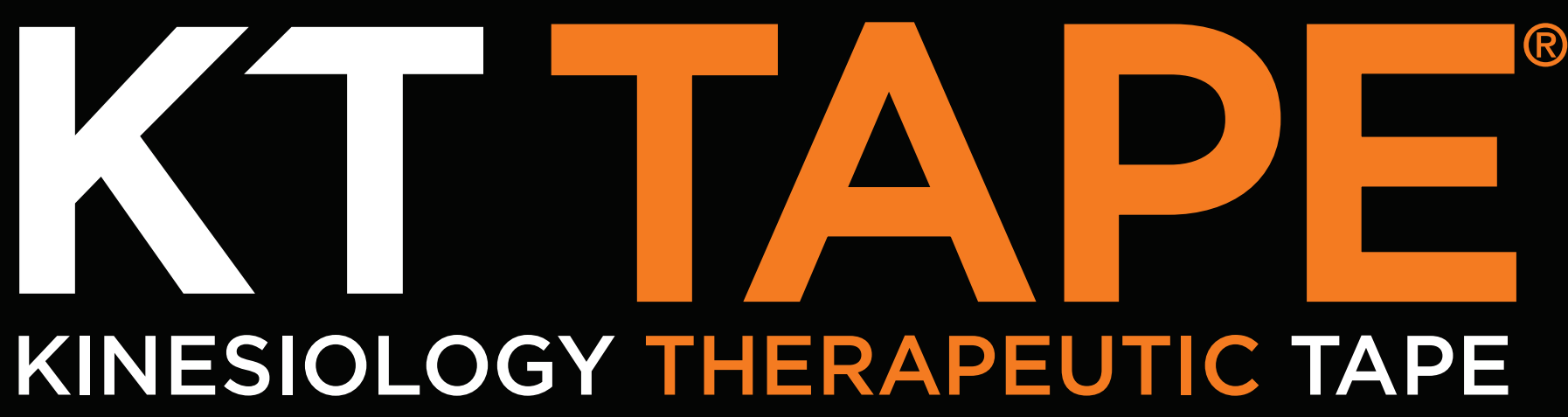

\section{- 6m Original Cotton Uncut Rolls - Beige, Black and Blue}

- R109 per Roll incl. VAT

\section{ELASTIC SPORTS TAPE FOR PAIN RELIEF AND SUPPORT}

For live video instructions visit KT TAPE online at sales@kttape.co.za www.kttape.com 


\begin{tabular}{|c|c|c|c|}
\hline Statement related to knowledge about health promotion. & $\begin{array}{l}\text { Yes } \\
\text { N (\%) }\end{array}$ & \begin{tabular}{|l|} 
No \\
N (\%)
\end{tabular} & $\begin{array}{l}\text { Unknown } \\
\text { N (\%) }\end{array}$ \\
\hline $\begin{array}{l}\text { K1. Health promotion activity involves building healthy policy to promote health of } \\
\text { the population }\end{array}$ & $238(90)$ & $2(1)$ & $24(9)$ \\
\hline $\begin{array}{l}\text { K2. HP intervention calls for professionals to be involved in improving and } \\
\text { maintaining healthy status for all }\end{array}$ & $257(97)$ & $2(1)$ & $5(2)$ \\
\hline $\begin{array}{l}\text { K3. Health promotion intervention involves early detection and prevention of } \\
\text { diseases }\end{array}$ & $241(91)$ & $13(5)$ & $10(4)$ \\
\hline K4. HP intervention involves strengthening community action to prevent diseases & $257(97)$ & 2(1) & $5(2)$ \\
\hline K5. HP intervention involves developing personal skills to stay healthy & $249(94)$ & $5(2)$ & $10(4)$ \\
\hline K6. Health education is a process of implementing health promotion & 246(93) & $7(3)$ & $11(4)$ \\
\hline K7. HP can be achieved through environmental modification & 207(78) & $12(5)$ & $45(17)$ \\
\hline K8. Disease prevention program such as vaccination is a method of health promotion & $242(92)$ & $10(4)$ & $12(4)$ \\
\hline K9. HP includes the implementation of lifestyle and behavioural change programs & 255(97) & $2(1)$ & $7(3)$ \\
\hline K10. HP calls for re-orientation of health services beyond clinical and curative services & $230(87)$ & $3(1)$ & $31(12)$ \\
\hline \multicolumn{4}{|l|}{ Level of knowledge about health promotion of physiotherapists in SA } \\
\hline Adequate knowledge (score $>60 \%$ ) & 244(92) & & \\
\hline Inadequate Knowledge (score $\leq 60 \%$ & $20(8)$ & & \\
\hline $\begin{array}{l}\text { Statement about attitude toward health promotion services in } \\
\text { physiotherapy practice. }\end{array}$ & $\begin{array}{l}\text { Agree } \\
\text { N (\%) }\end{array}$ & $\begin{array}{l}\text { Disagree } \\
\mathbf{N}(\%)\end{array}$ & \begin{tabular}{|l|} 
Neutral \\
N (\%)
\end{tabular} \\
\hline A1. Physiotherapists are well positioned to integrate HP in practice & $227(86)$ & $13(5)$ & $24(9)$ \\
\hline A2. Physiotherapists should be involved in the efforts to promote physical activity & $219(83)$ & $8(3)$ & $37(14)$ \\
\hline $\begin{array}{l}\text { A3. HE on healthy diet and promotion of physical activity should be part of physi- } \\
\text { otherapy treatment }\end{array}$ & $213(81)$ & $12(4)$ & $39(15)$ \\
\hline $\begin{array}{l}\text { A4. Physiotherapists should be involved in educating people about ergonomics in } \\
\text { their communities }\end{array}$ & $247(94)$ & $3(1)$ & $14(5)$ \\
\hline $\begin{array}{l}\text { A5. Physiotherapists should participate in developing health and safety regulations } \\
\text { for a healthy environment }\end{array}$ & $217(82)$ & $3(1)$ & $44(17)$ \\
\hline A6. The health educator role is appropriate for physiotherapists & $226(86)$ & $5(2)$ & $33(12)$ \\
\hline $\begin{array}{l}\text { A7. Physiotherapists should align practice to health promotion efforts of the } \\
\text { Department of Health }\end{array}$ & $214(81)$ & $8(3)$ & $42(16)$ \\
\hline A8. HP should form an integral part of physiotherapy at all level of health care & 245(93) & $2(1)$ & $17(6)$ \\
\hline A9. Provision of time allocated for treatment should be made for integrating HP & 215(82) & $6(2)$ & $43(16)$ \\
\hline A10. There should be a fee payable for HP integration by medical schemes & 183(69) & $25(10)$ & $56(21)$ \\
\hline \multicolumn{4}{|l|}{ Attitude levels amongst physiotherapists in SA } \\
\hline Positive attitude (score $>60 \%$ ) & 209(79) & & \\
\hline Negative attitude (score $\leq 60 \%$ ) & $55(21)$ & & \\
\hline Statement about integration of health promotion in physiotherapy practice. & $\begin{array}{l}\text { Always } \\
\text { N (\%) }\end{array}$ & $\begin{array}{l}\text { Often } \\
\mathbf{N}(\%) \\
\end{array}$ & $\begin{array}{l}\text { Never } \\
\text { N (\%) }\end{array}$ \\
\hline P1. HP is part of my responsibility & $179(68)$ & $76(29)$ & $9(3)$ \\
\hline $\begin{array}{l}\mathrm{P} 2 . \mathrm{HP} \text { is integrated in physiotherapy treatment when the patient is aware of the } \\
\text { problem and desires to improve }\end{array}$ & $187(71)$ & $70(26)$ & $7(3)$ \\
\hline P3. All patients are educated about health related risks & $108(41)$ & $146(55)$ & $10(4)$ \\
\hline P4. Emotional support is provided to patients when no any other support is available & $124(47)$ & $122(46)$ & $18(7)$ \\
\hline P5. Patients are encouraged to talk about their health problems & $79(30)$ & $161(61)$ & 24(9) \\
\hline P6. Patients are educated about available health resources in their communities & 103(39) & $139(53)$ & $22(8)$ \\
\hline P7. Patients are assisted to make healthier choices & $119(45)$ & $128(49)$ & $17(6)$ \\
\hline P8. Health education and physical activity are included in treatment & 166(63) & 92(35) & $6(2)$ \\
\hline $\begin{array}{l}\text { P9. Health education is integrated in treatment of all patients from low socio-eco- } \\
\text { nomic background }\end{array}$ & $127(48)$ & $117(44)$ & $20(8)$ \\
\hline P10. Health education is also included when there is support of a referring doctor & $100(38)$ & $138(52)$ & $26(10)$ \\
\hline P11. Physical activity is included when supportive materials are available & 154(58) & 92(35) & $18(7)$ \\
\hline \multicolumn{4}{|l|}{ Level of health promotion practices among physiotherapists in SA } \\
\hline Adequate practice (score $>60 \%$ ) & $126(48)$ & & \\
\hline Inadequate practice (score $\leq 60 \%$ ) & $138(52)$ & & \\
\hline
\end{tabular}


The older age group (99\%) showed significantly better knowledge $(\mathrm{p}=.02)$ than the younger age group (90\%) (Table3). Similarly, physiotherapists with over 10 years of experience $(96 \%)$ had significantly better knowledge than those with less years of experience $(89 \%)(p=.01)$. Physiotherapists having an HP certificate having attended a continuous education course in HP, showed better knowledge $(100 \%$ and $96 \%)$ than those who did not have a certificate $(92 \%)$ or had not attended a course $(91 \%)$ although this finding was not significant.

\section{Attitudes}

Respondents (94\%) stated that physiotherapists should be involved in educating people about ergonomics in their communities (Table 2). Ninety three percentage $93 \%$ felt that HP should form an integral part of physiotherapy at all levels of health care, and $86 \%$ considered themselves well positioned to integrate HP. Many physiotherapists surveyed $(86 \%)$ supported the notion that the health educator role is appropriate for physiotherapists. Approximately $82 \%$ of all physiotherapists surveyed agreed that physiotherapists should be involved in developing health and safety regulations for a healthy environment. Many of the respondents agreed that there is a need for physiotherapy to align practice to health promotion efforts of the health department (81\%). About $81 \%$ respondents agreed that provision of time in the allocated treatment session should be made for integrating HP during treatment. HE on diet and promotion of physical activity as part of physiotherapy practice was supported by $81 \%$ of the participants. More than half of the respondents $(69 \%)$ believed that a fee must be payable for HP interventions by medical schemes. Overall, almost three quarters of physiotherapists surveyed reflected positive attitudes $(79 \%)$ with a median score of $9(\mathrm{SD}=1.93)$. Test statistics established no differences of attitude amongst physiotherapists with different socio-demographics and work experience (Table 3). Only adequate knowledge was correlated with a positive attitude towards HP ( $p=.002)$.

\section{Practice}

Of all respondents, only $68 \%$ always regarded HP as their responsibility. However, a few (30\%) encouraged patients to talk about their health problems (Table 2). Approximately $71 \%$ integrated HP when the patient was aware of the problem and desired to improve. Both $\mathrm{HE}$ and physical activity were included in treatment by about two thirds of the respondents $(62.9 \%)$. Less than half of the respondents $(41 \%)$ educated their patients about health- related risks while a few provided emotional support to patients in stress (47\%). Only $48 \%$ integrated $\mathrm{HE}$ in treatment of all patients from a low socio-economic background. HE was always included by a minority $(38 \%)$ in their practice when there was support provided by the referring doctor, whereas physical activity was always included in treatment when there were supportive materials by about half of the respondents (58\%). Approximately a third (39.0\%) educated their patients about health resources available in the community and less than half (45\%) also assisted patients to make healthier choices. Less than half of the respondents had a high practice score (48\%) with a median score of $8(\mathrm{SD}=1.93)$.

\section{Predictors of HP practice}

Working experience $(p=.047)$, receiving HP training $(p=.001)$, HP certificate $(\mathrm{p}=.01)$, attending continuous education courses $(p=.009)$, sufficient knowledge on HP $(p=.04)$ and positive attitude towards HP $(\mathrm{p}=.001)$ were all significantly associated with acceptable practices. After adjustment, stepwise modelling, more than 10 years' working experience (aOR: $2.57 ; \mathrm{p}=.002)$, HP training (aOR: $3.97 ; \mathrm{p}=.001$ ) and positive attitude of the physiotherapists (aOR: 2.54; $\mathrm{p}=.007$ ) were the best predictors of acceptable HP practice in physiotherapy. Indeed, experience was confounded by age, as virtually all participants over $40 \mathrm{yrs}$ (and implicitly with $>10$ years of experience) had good knowledge. Good knowledge was a predictor of positive attitude and is part of a causality chain.

\section{DISCUSSION}

The majority of physiotherapists are knowledgeable about HP and have a positive attitude towards integration of HP during physiotherapy. However, only a few include HP during their physiotherapy sessions. In our study, settings, sectors and training institutions have not affected the knowledge, attitude and practices domains in SA. The only predictors of HP practice are training in $\mathrm{HP}$, working experience, and a positive attitude. The latter is found to be associated with sufficient knowledge.

This is the first comprehensive study assessing HP among physiotherapists in SA working in various health care sectors. The study had an expected response rate for a postal survey among health professionals (Cook et al., 2009) and Cronbach's reliability tests were strong. Females constituted the majority of the study respondents, correlating with the current status in a profession which was initially dominated by females (WCPT, 2007). This working group comprised many young adults between the age of 21 and 40 years. similar characteristics to those found amongst other health professionals (Laliberte et al., 2012; Cook et al., 2009).

Lack of knowledge has been cited as a possible barrier to practice (Rabiei et al, 2012; Achhra, 2009). The current study showed that physiotherapists possess high knowledge about HP which could work as an advantage towards HP integration in patient care. Perreault (2008) asserted that physiotherapists knowledgeable in HP are more likely to play an important role in promoting the health of their patients. Despite the majority of practitioners scoring high in the knowledge component, some knowledge gaps do exist and have a potential to affect the application in practice. Other health professionals reported that lack of knowledge does indeed affect their health promotion practice (Achhra, 2009; Wechsler H et al., 1996). Most general practitioners were found to be unsure of the health promotion definition, which was related to a gap in the skills and training about health promotion. Furthermore, lack of understanding about principles of HP was identified as a barrier to integration into practice by some health professionals as well (Achhra, 2009). While the present study found knowledge to be associated with 


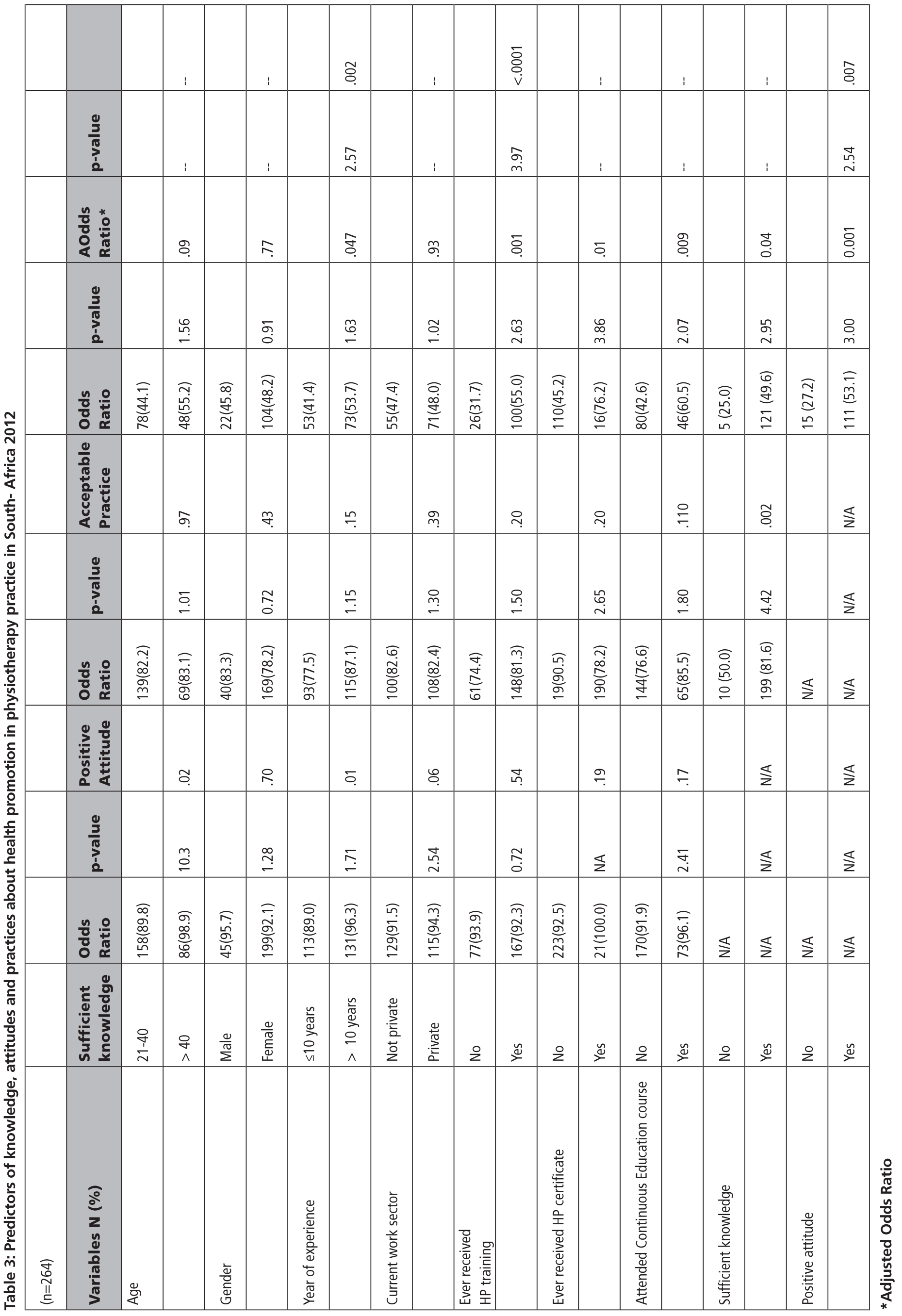


attitude, and attitude to practice, an almost similar study reported that the physiotherapists' level of confidence had a significant influence on their HP integration in practice too (Rea et al., 2004). The majority of physiotherapists were aware that physiotherapy practice should be aligned to HP efforts of the government and agreed that time must be allocated in the treatment schedule for HP. It was encouraging that physiotherapists had generally positive attitudes towards HP in physiotherapy practice and believed that physiotherapists are well positioned to provide HP interventions. The majority agreed that HP should form an integral part of physiotherapy. This finding is in line with other studies conducted elsewhere, in which physiotherapists considered their role as important in promoting the health of their patients (Healey et al., 2012; Mulligan et al., 2011; Shirley et al., 2010; Johansson et al., 2009).

In the present study, only $48 \%$ of the study group scored positively on all aspects of HP integration in practice, which is not encouraging compared to the $56 \%$ found in the USA (Rea et al., 2004) which was said to be unacceptable. These results are coherent with the findings of the first physiotherapy summit on global health. This summit also iterated the low level of the proportion of practitioners practising in the area of HP (Dean et al, 2011). The subsequent recommendation stipulates that even in a conventional orthopaedic physiotherapy practice, the lifestyle-related conditions need to be given priority for the patients' health and well-being to avert consequences of lifestyle-related conditions (Dean et al., 2011).

There is a lack of patients' support for promotion of health in physiotherapy practice which is not in alliance with a definition of HP by Downie et al. (1996) "as efforts to enhance positive health and reduce the risk of ill-health, through overlapping spheres of health education (HE), health prevention" (Downie et al., 1996: p26) and provision of patient support. HE is not a commonly used HP strategy in practice a contrast to other research findings (Hills, 1995). In her review, Perreault (2008) found the most commonly used HP strategy among physiotherapists was health education. Health education interventions enable the individuals to acquire knowledge that enables them to find a balance between lifestyle and optimal control of health (Touillet et al., 2010) yet it is lacking in practice among surveyed physiotherapists. Physiotherapists are encouraged to use their one-on-one encounter with a patient as an important source of health information by patients and the community (Dean, 2009). The uncommon inclusion of physical activity asserts the lack of physiotherapy involvement in this area, given their strong training background in movement (Verhagen and Engbers, 2009). The lack of support for those who are in need, such as patients with stress, indicated that physiotherapists were not using the advantage of the unique physiotherapy pattern which entails prolonged interactions over a long period of time inherent in the profession to influence patients' behaviour for good health (Frerichs et al., 2012). This skills gap could be a sequel of the behaviour change competency reported to be lacking among physiotherapists (Dean, de Andrade et al., 2014).

Promising in our findings was the effect of undergraduate training on practice, which could be used as a strategy to encourage more HP practice through running a number of continuing professional development programmes. Positive attitude is also a predictor of acceptable HP practice in physiotherapy, and therefore the profession and policy makers should put in place strategies to change the attitude of all physiotherapists. Another encouraging fact was that almost all physiotherapists believed that HP should form an integral part of physiotherapy at all levels of health care. Other health professionals have identified a significant role to play in HP and prevention yet have realised a wide gap exists between their ideal and actual levels of involvement (Johansson et al., 2010) an aspect which could be pursued among physiotherapists in future studies (Achhra, 2009). Physiotherapists are advised that the focus of professional interest should be in competencies associated with effective health education and health behaviour change internationally in the 21 st century. The results of this study signify that further studies are needed to assess the content of HP in the curricula of the different training institutions in SA. Focus should also be put on HP integration into curricula at undergraduate, graduate and continuing professional development levels.

The HP training referred to is obtained at the undergraduate level, and a similar continuous education programme could be a steppingstone towards improved HP practice if the current status of physiotherapy involvement is to be improved. The contribution of work experience towards acceptable HP practices could be linked to the participants having acquired competencies applicable to identifying HP needs among patients seen during practice, and thus hold hope for better patient care in coming years from the current workforce.

Limitations: Although the crosssectional design allows investigation of potential links between knowledge, attitude and practice and other causalities, longitudinal study designs and qualitative study designs may offer additional insights or suggest alternative strategies. The sample size failed to reach the anticipated total for generalisability; hence the findings are only applicable to the physiotherapists who participated in the study.

\section{CONCLUSION}

The majority of South African physiotherapists reflected a high level of knowledge and positive attitude; however, a gap does exist between knowledge and skills about health promotion practice in physiotherapy. This gap has a potential to affect application in practice. Practitioners reflected suitable attitudes towards health promotion, with a potential for successful health promotion in physiotherapy practice. Short training and continuing professional education courses are a probable solution to the improvement and integration of the health promotion by all practitioners, as well as a good effect on the low health promotion practice level. In this way the anticipated subsequent provision of health promotion interventions contributing towards controlling the upcoming 
chronic disease epidemic in South (ern) Africa would be facilitated

\section{ETHICAL CONSIDERATIONS}

Ethical clearance was obtained from the ethics committee (MREC) at University of Limpopo-Medunsa campus (MREC10/8/20). Written informed consent was obtained and a confidentiality form was signed by all participants.

\section{DECLARATION OF INTEREST}

The authors report no declaration of interest. Travel grants were provided by (1) the Belgium Development Co-operation through VLIR-UOS in the framework of institutional collaboration between the University of Limpopo and the Flemish Universities, Belgium; and (2) an Erasmus Mundus scholarship.

\section{REFERENCES}

Achhra A (2009) Health promotion in Australian general practice: a gap in GP training. Australian Family Physician 38(8): 605-608.

Church TS, Blair SN (2009) When will we treat physical activity as a legitimate medical therapy... even though it does not come in a pill? British Journal of Sports Medicine 43(2): 80-81.

Cook JV, Dickinson HO, Eccles MP(2009) Response rates in postal surveys of healthcare professionals between 1996 and 2005: an observational study. BMC.Health Service Research 9: 160.

Dean E (2009) Physical therapy in the 21st century (Part I): toward practice informed by epidemiology and the crisis of lifestyle conditions. Physiotherapy Theory and Practice 25(5-6): 330-353.

Dean E, Al-Obaidi S, De Andrade AD, Gosselink R, Umerah G, Al-Abdelwahab S, et al. (2011) The First Physical Therapy Summit on Global Health: implications and recommendations for the 21st century. Physiotherapy Theory and Practice 27(8): 531-547.

Dean, E., de Andrade, A. D., O'Donoghue, G., Skinner, M., Umereh, G., Beenen, P. et al. (2014) The Second Physical Therapy Summit on Global Health: developing an action plan to promote health in daily practice and reduce the burden of non-communicable diseases. Physiotherapy Theory and Practice 30(4): 261-275.

Department Of Health (2010) Strategic Plan 2010/11-2012/2013.[Internet] Available from www.doh.gov.za/

Downie RS, Tannahill A, Tannahill C (1996) Health promotion models and values, Oxford University Press, NEW YORK.
Frantz JM (2008) Advocating Evidence based Health Promotion in Physiotherapy. The South African Journal of Physiotherapy 28(1): 28-30.

Frerichs W, Kaltenbacher E, van de Leur JP, Dean E (2012) Can physical therapists counsel patients with lifestyle-related health conditions effectively? A systematic review and implications. Physiotherapy Theory and Practice 28(8): 571-587.

Healey WE, Broers KB, Nelson J, Huber G (2012) Physical therapists' health promotion activities for older adults. Journal of Geriatric Physical Therapy 35(1): 35-48.

Hills R (1995) The role of the physiotherapist in Health Education. Physiotherapy 5: 270.

Johansson H, Stenlund H, Lundstrom L, Weinehall L (2010) Reorientation to more health promotion in health services - a study of barriers and possibilities from the perspective of health professionals. Journal of Multidisciplinary Healthcare 3: 213-224.

Johansson H, Weinehall L, Emmelin M (2009) "It depends on what you mean": a qualitative study of Swedish health professionals' views on health and health promotion. BMC.Health Service Research 9: 191.

Jones SC, Donovan RJ (2004) Does theory inform practice in health promotion in Australia? Health Education Research 19(1): 1-14.

Laliberte MC, Perreault S, Damestoy N, Lalonde L (2012) Ideal and actual involvement of community pharmacists in health promotion and prevention: a cross-sectional study in Quebec, Canada. BMC. Public Health 12: 192.

Mulligan H, Fjellman-Wiklund A, Hale L, Thomas D, Hager-Ross C (2011) Promoting physical activity for people with neurological disability: perspectives and experiences of physiotherapists. Physiotherapy Theory and Practice 27(6): 399410 .

Perreault K (2008) Linking health promotion with physiotherapy for low back pain: a review. Journal of Rehabilitation Medicine 40(6): 401-409.

Rabiei S, Mohebbi SZ, Patja K, Virtanen JI (2012) Physicians' knowledge of and adherence to improving oral health. BMC.Public Health 12: 855 .

Rea BL, Hopp MH, Neish C, Davis N (2004) The role of health promotion in physical therapy in California, New York, and Tennessee. Physical Therapy 84(6): 510-523.

Ritchie J (1989) Keeping Australians Healthy:The challenge to Physiotherapy practice by the concept of the new public health. The Australian Journal of Physiotherapy 35(2): 101-107.

Shirley D, van der Ploeg HP, Bauman AE (2010) Physical activity promotion in the physical therapy setting: perspectives from practitioners and students. Physical Therapy 90(9): 1311-1322.

Taukobong NP, Myezwa H, Pengpid S, Van Geertruyden JP (2014) The degree to which physiotherapy literature includes physical activity as a component of health promotion in practice and entry level education: a scoping systematic review. Physiotherapy Theory and Practice 30(1): 12-19.

Touillet A, Guesdon H, Bosser G, Beis JM, Paysant J (2010) Assessment of compliance with prescribed activity by hemiplegic stroke patients after an exercise programme and physical activity education. Annals of Physical Rehabilitation Medicine 4: 250-265.

Verhagen E, Engbers L (2009) The physical therapist's role in physical activity promotion. British Journal of Sports Medicine 43(2): 99-101.

World Confederation for Physical Thearpists (2007) Declaration of Principle.[Internet] Available from www.wcpt.org

Wechsler H, Levine S, Idelson RK, Schor EL and Coakley E (1996) The Physician's role in health promotion re-visied: a survey of primary care practitioners. The New England Journal of Medicine996-998.

World Health Oragnisation (1986) The Ottawa Charter for Health Promotion.[Internet] Available from www.who.int./healthpromotion

World Health Organisation (2007) The international Network of Health Promoting Hospitals and Health services.[Internet] Available from www.healthprotinghospitals.org

World Health Organisation (2011) WHPA Health imrpovement card-User guide for health professionals. Global status on non- communicable diseases in 2010. 